\title{
Characterising rates and chemistry of basalt dissolution in agriculture soil cores to assess potential of enhanced weathering
}

\author{
FRANCES L. BUCKINGHAM ${ }^{1}$, PHIL HOLDSHIP ${ }^{1}$, PHIL \\ RENFORTH $^{2}$ AND GIDEON M HENDERSON ${ }^{1}$ \\ ${ }^{1}$ University of Oxford \\ ${ }^{2}$ Heriot-Watt University \\ Presenting Author: frances.buckingham@earth.ox.ac.uk
}

Weathering of silicate minerals is a natural process that removes $\mathrm{CO}_{2}$ from the atmosphere, helping to regulate atmospheric $\mathrm{CO}_{2}$ on geological timescales. The application of silicate minerals to agricultural soils has been suggested as a route to enhance weathering rates and increase $\mathrm{CO}_{2}$ drawdown. The potential for such enhanced weathering as a $\mathrm{CO}_{2}$ removal technique remains uncertain due to (i) conflicting estimates for mineral dissolution rates in soils (ii) poor understanding of the pathway of inorganic carbon through the terrestrial, river and marine ecosystem (iii) the unknown geochemical and environmental impact of silicate dissolution on these ecosystems. Laboratory and field studies have attempted to address these issues but produce equivocal results. The use of soil cores addresses the limitations of both laboratory and field studies by maintaining the complexities of the soil zone in an environment where variables can easily be isolated and measured.

In this study, soil cores taken from a typical UK agricultural site were treated with crushed basalt and exposed to variations in UK weather and temperature throughout a 15-month experiment. Chemical measurements in soil water at up to 10 depths in the soil and in effluent leaving the base of the core provide insights into cation release rates from the basalt, and the fate of dissolved products in the soil. These measurements constrain the preferential dissolution of minerals in the basalt and therefore the $\mathrm{CO}_{2}$ sequestration potential of basalt in agricultural soils. Our soil core study provides novel insights into critical geochemical processes which influence the efficacy of large scale enhanced weathering; such as preferential phase dissolution, heavy metal retention, secondary precipitation and their impacts on the terrestrial and marine environment. 